Article

\title{
Aflibercept Nanoformulation Inhibits VEGF Expression in Ocular In Vitro Model: A Preliminary Report
}

\author{
Shannon J. Kelly ${ }^{1}$, Anjali Hirani ${ }^{1}$, Vishal Shahidadpury ${ }^{1}$, Aum Solanki ${ }^{1}$, Kathleen Halasz ${ }^{1}$, \\ Sheeba Varghese Gupta ${ }^{1}$, Brian Madow ${ }^{2}$ and Vijaykumar Sutariya ${ }^{1, *}$ \\ 1 Department of Pharmaceutical Sciences, College of Pharmacy, University of South Florida, Tampa, FL 33612, \\ USA; shannonk@health.usf.edu (S.J.K.); ahirani@gmail.com (A.H.); vpury89@gmail.com (V.S.); \\ solankia@health.usf.edu (A.S.); halaszk@health.usf.edu (K.H.); svarghes@health.usf.edu (S.V.G.) \\ 2 Department of Ophthalmology, College of Medicine, University of Florida, Jacksonville, FL 32209, USA; \\ Brian.madow@jax.ufl.edu \\ * Correspondence: vsutariy@health.usf.edu; Tel.: +1-813-974-1401
}

Received: 8 August 2018; Accepted: 6 September 2018; Published: 11 September 2018

check for updates

\begin{abstract}
Age-related macular degeneration (AMD) is one of the leading causes of blindness in the United States, affecting approximately 11 million patients. AMD is caused primarily by an upregulation of vascular endothelial growth factor (VEGF). In recent years, aflibercept injections have been used to combat VEGF. However, this treatment requires frequent intravitreal injections, leading to low patient compliance and several adverse side effects including scarring, increased intraocular pressure, and retinal detachment. Polymeric nanoparticles have demonstrated the ability to deliver a sustained release of drug, thereby reducing the necessary injection frequency. Aflibercept (AFL) was encapsulated in poly lactic-co-glycolic acid (PLGA) nanoparticles (NPs) via double emulsion diffusion. Scanning electron microscopy showed the NPs were spherical and dynamic light scattering demonstrated that they were uniformly distributed $(\mathrm{PDI}<1)$. The encapsulation efficiency and drug loading were $75.76 \%$ and $7.76 \%$ respectively. In vitro release studies showed a sustained release of drug; $75 \%$ of drug was released by the NPs in seven days compared to the full payload released in $24 \mathrm{~h}$ by the AFL solution. Future ocular in vivo studies are needed to confirm the biological effects of the NPs. Preliminary studies of the proposed aflibercept NPs demonstrated high encapsulation efficiency, a sustained drug release profile, and ideal physical characteristics for AMD treatment. This drug delivery system is an excellent candidate for further characterization using an ocular neovascularization in vivo model.
\end{abstract}

Keywords: age-related macular degeneration; vascular endothelial growth factor; aflibercept; nanoparticles; PLGA

\section{Introduction}

A decrease in visual acuity can lead to alterations in the activities of daily living, quality of life, self-care, and mental health of an individual. A disease commonly responsible for this visual impairment is age-related macular degeneration (AMD). AMD is a degenerative disease of the macula and it affects the part of the retina responsible for sharp, detailed central vision. AMD is the most prominent cause of vision loss in people 50 years and older in North America and it is expected to affect 7.5 million people by 2020 in the United States [1]. Several factors influence the prognosis and progression of AMD, including genetic variation, living environment, and lifestyle [2]. 
Neovascular or "wet" AMD accounts for more than $90 \%$ of individuals with advanced vision loss. The distinctive feature of neovascular AMD is choroidal neovascularization (CNV), which is regulated by growth factors including vascular endothelial growth factor (VEGF) [1]. In CNV there is an abnormal proliferation of new blood vessels originating from the choroid, leading to sub- and intra-retinal macular edema, fluid leakage, bleeding, and fibrosis of retinal tissue. This results in severe visual deterioration [3].

Amongst the VEGF family of growth factors, VEGF-A is a signal protein that promotes angiogenesis and vascular leakage in the retina. VEGF's biological properties arise from binding to trans-membrane VEGF receptors (VEGFR) on vascular endothelial cells. VEGF-A specifically binds to VEGFR-1 in the process of inflammatory neovascularization [2]. However, VEGFR-2 is responsible for triggering many of the proangiogenic functions of VEGF-A [4]. Drugs known as anti-VEGF agents have been designed to block this binding of VEGF, thereby limiting its damage to the eye. To date, the FDA has approved three anti-VEGF agents for ocular applications: Ranibizumab, pegaptanib, and aflibercept [5]. Aflibercept (AFL) is a fusion protein containing both VEGFR-1 and VEGFR-2, which binds to VEGF-A thus impeding its activity [2]. AFL's prolonged duration of action is attributed to its distinctive binding activity. By blocking the VEGF signal with AFL, it has been shown there is stabilization and even reversal in the vision loss normally associated with neovascular AMD [3].

Many of the adverse effects of Anti-VEGF agents originate from their route of administration. Intravitreal injections are perhaps the most common mode of administration to the posterior segment. However, anti-VEGF agents possess a narrow therapeutic index, thereby necessitating frequent injections to maintain an acceptable concentration of drug in the eye [6]. This frequency not only reduces patient compliance, but also results in myriad potential adverse effects including retinal detachment, vitreous hemorrhage, and increased intraocular pressure [7,8]. Ocular protein delivery has the added challenges of short protein half-life and degradation by enzymes [9]. Polymeric nanoparticles deliver a targeted sustained release of drug, thereby reducing the injection frequency and related effects [10], as well as providing a therapeutic dose of protein with limited toxicity [11]. Furthermore, nanoparticles have demonstrated the ability to localize on the retinal pigment epithelium (RPE), an ideal trait for the amelioration of AMD [12].

Polymeric nanoparticles (NPs) can be prepared using various natural or synthetic materials. Poly lactic-co-glycolic acid (PLGA) is a biodegradable synthetic polymer which is commonly used for the preparation of NPs. The widespread use of PLGA in recent studies is partly due to its ability to demonstrate a sustained drug release with a low cytotoxicity and minimal side effects $[13,14]$. PLGA can be used to encapsulate hydrophobic or hydrophilic materials and the shape and size of PLGA NPs are easily manipulated [15]. For instance, Booysen et al. recently used PLGA to encapsulate vancomycin in a nanoformulation. The NPs were $247 \mathrm{~nm}$ but did not possess uniformity when analyzed under SEM. Regardless, the NPs were more effective in combating MRSA than a solution of free vancomycin [16]. Sanchez et al. used PLGA microspheres to encapsulate the macromolecule interferon-alpha (IFN- $\alpha$ ). The sustained release and anti-proliferative activity of the microspheres indicate that this is a suitable in vitro platform for macromolecule delivery [11]. Feczko et al. studied the encapsulation of the protein bovine serum albumin (BSA) under various conditions. Using the double emulsion solvent evaporation method, PLGA nanoparticles encapsulating the protein were successfully produced with high encapsulation efficiencies [17]. Later, Swed et al. encapsulated lysozyme and human transforming growth factor beta 1 (TGF- $\beta 1$ ) separately in PLGA NPs to examine protein encapsulation. They found that the NPs encapsulated at least $50 \%$ of each protein and possessed both a uniform size distribution (PDI less than 0.2) and sustained release properties over 30 days. Blank NPs were nontoxic to NIH3T3, HS68 and hATSC cells after 48 h; in fact the assay showed significant cell proliferation with increasing concentrations of NPs [18]. It may therefore be concluded that PLGA NPs are an appropriate mode of protein delivery.

There are several methods by which PLGA NPs can be produced. In this work, NPs containing AFL (AFL-NPs) were prepared via double emulsion diffusion using the synthetic biodegradable 
polymer PLGA. The NPs were then characterized for their physical characteristics, encapsulation efficiency, and sustained release profile. The cytotoxicity and efficacy of the NPs in human retinal pigment epithelial (ARPE-19) cells were determined via MTT assay and ELISA. By doing so, it was demonstrated that a high encapsulation efficiency, uniform size distribution and sustained drug release were achieved by the nanoformulation of the protein AFL.

\section{Experimental Section}

\subsection{Materials}

Aflibercept (Eylea, $2 \mathrm{mg} / 0.05 \mathrm{~mL}$ ) (Regeneron Pharmaceuticals, Inc., Tarrytown, NY, USA) was generously donated by Dr. Brian Madow of the USF Eye Institute. ARPE-19 cells (ATCC ${ }^{\circledR}$ CRL2302 ${ }^{\mathrm{TM}}$ ) and DMEM: F-12 were ordered from the American Type Culture Collection (ATCC) (Manassas, VA, USA). $1 \times$ Dulbecco's Modified Eagle's Medium (DMEM) and 10 $\times$ phosphate buffered saline (PBS) were purchased from Mediatech, Inc. (Manassas, VA, USA). PLGA-COOH (DL-lactide-co-glycolide) (PLGA) was obtained from LACTEL Absorbable Polymers (DURECT Corporation, Pelham, AL, USA). Dichloromethane (Chromasolv-HPLC grade), heat-inactivated fetal bovine serum, thiazoyl blue tetrazolium bromide (MTT reagent), and methanol (Chromasolv-HPLC grade) were purchased from Sigma-Aldrich (St. Louis, MO, USA). Polyvinyl alcohol (PVA) was purchased from Fisher Scientific (Pittsburgh, PA, USA). D-Mannitol was obtained from Acros Organics (Geel, Belgium). Slide-A-Lyzer Dialysis Cassettes (Extra Strength; 10,000 MWCO) were purchased from Thermo Scientific (Waltham, MA, USA).

\subsection{Nanoparticle Preparation}

The double-emulsion diffusion method was used to prepare AFL NPs (Figure 1). One milligram of AFL ( $25 \mu \mathrm{L}$ stock solution) was added to $100 \mu \mathrm{L} 1 \times$ PBS and a separate solution of $4.5 \mathrm{mg}$ PLGA was prepared in $1 \mathrm{~mL}$ dichloromethane (DCM). These solutions were combined and emulsified using sonication at $9.5 \mathrm{~W}$ for approximately $30 \mathrm{~s}$. After the dropwise addition of $2 \mathrm{~mL} 1 \% w / v$ PVA, the suspension was emulsified via sonication at $9.5 \mathrm{~W}$ for another $30 \mathrm{~s}$. The emulsion was stirred at $500 \mathrm{rpm}$ overnight at $4{ }^{\circ} \mathrm{C}$ to allow diffusion. The emulsion was split into two fractions and centrifuged at $20,000 \times g$ at $4{ }^{\circ} \mathrm{C}$ for $15 \mathrm{~min}$. Each pellet was then resuspended in $1 \mathrm{~mL} \%$ w/v mannitol. Blank NPs were prepared similarly excluding the addition of AFL.

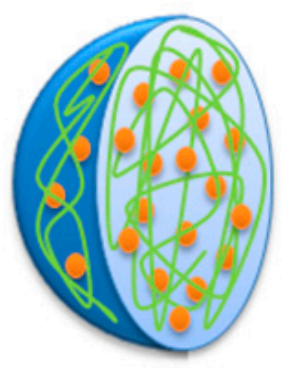

Drug

\section{Polymer}

(A)
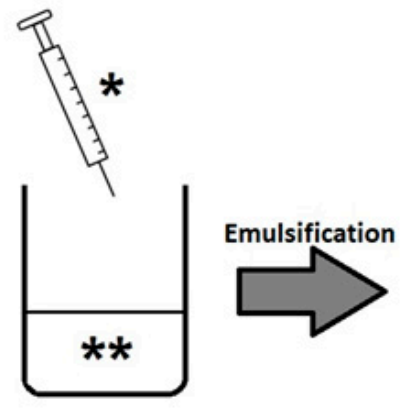

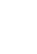
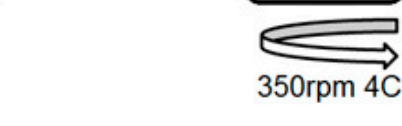

(B)

Figure 1. (A) Aflibercept nanoparticles were prepared via (B) the double emulsion diffusion method ( ${ }^{*}$ aqueous phase; ${ }^{* *}$ organic phase). 


\subsection{Nanoparticle Characterization}

The size and polydispersity index (PDI) of both the AFL and blank NPs were analyzed via dynamic light scattering (DLS) using a Wyatt DynaPro plate reader (Wyatt Technology Corporation, Santa Barbara, CA, USA). The NPs were diluted 1:200 in filtered deionized water to meet equipment specifications and analyzed in triplicate.

\subsection{Scanning Electron Microscopy (SEM)}

The NPs were viewed via SEM using a JOEL JSM-6490LV (JOEL Industries, Tokyo, Japan). Samples were diluted 1:10 in filtered deionized water and adhered to aluminum cylinders using a carbon polymer adhesive. All images were obtained using a $5 \mathrm{kV}$ acceleration voltage.

\subsection{Encapsulation Efficiency and Drug Loading}

The encapsulation efficiency (EE) and drug loading (DL) of the NP formulation was calculated using the concentration of drug present in a $1 \mathrm{~mL}$ sample of the NPs. After centrifugation at $15,000 \times g$ for $5 \mathrm{~min}$, the NPs were suspended in methanol and placed at $4{ }^{\circ} \mathrm{C}$ overnight to dissolve the NPs. Both this sample and a standard curve of AFL in methanol were prepared using the Pierce BCA protein assay (Thermo Scientific, Waltham, MA, USA) and analyzed via VIS spectroscopy at $562 \mathrm{~nm}$ on a BioTek Synergy H4 plate reader (BioTek Instruments Inc., Winooski, VT, USA). The standard curve was used to convert the absorbance of the NP sample to a concentration. EE and DL were calculated as follows:

$$
\begin{gathered}
\% \mathrm{EE}=(\text { Mass of entrapped drug }) /(\text { Total mass of drug }) \times 100 \% \\
\% \mathrm{DL}=(\text { Mass of entrapped drug }) /(\text { Mass of entrapped drug }+ \text { Mass of polymer }) \times 100 \% .
\end{gathered}
$$

\subsection{In Vitro Release Studies}

An in vitro release study was conducted according to a previously reported method [19]. Dialysis membrane cassettes were soaked in $1 \times$ PBS at $4{ }^{\circ} \mathrm{C}$. Approximately $500 \mu \mathrm{L}$ of AFL-NPs or AFL solution were inserted into the membrane and suspended in $100 \mathrm{~mL}$ PBS at $37^{\circ} \mathrm{C}$. Aliquots were removed and replaced with preheated PBS at regular intervals over a period of seven days. The collected samples were analyzed via BCA Protein Assay and read using spectroscopy at $562 \mathrm{~nm}$ with the Synergy H4 plate reader (Biotek Industries, Inc., Winooski, VT, USA). These values were compared to a calibration curve of AFL in $1 \times$ PBS to determine the cumulative percent of drug released at each interval.

\subsection{Cell Culture}

Human retinal pigment epithelial (ARPE-19) cells (ATCC ${ }^{\circledR}$ CRL2302 ${ }^{\mathrm{TM}}$ ) were grown in $1 \times$ Dulbecco's Modified Eagle's Medium (DMEM) with 10\% $v / v$ fetal bovine serum (FBS). Cells were kept in a Thermo Scientific Forma Steri-Cycle incubator (Fisher Scientific, Pittsburgh, PA, USA) at $37^{\circ} \mathrm{C}$ and $5 \%$ carbon dioxide.

\subsubsection{Cytotoxicity}

The cytotoxicity of the AFL-loaded and blank NPs in ARPE-19 cells was measured using the 3-(4,5-dimethylthiazol-2-yl)-2,5-diphenyltetrazolium bromide salt (MTT) assay [12]. ARPE-19 cells were seeded in a 48 -well plate and incubated at $37{ }^{\circ} \mathrm{C}$ with $5 \% \mathrm{CO}_{2}$ for $48 \mathrm{~h}$ to achieve confluence. Cell culture media was aspirated and the cells were treated with each of the NP formulations at final concentrations of $0.5 \mu \mathrm{M}$ and $1 \mu \mathrm{M}$. After a 24 -h incubation period, $300 \mu \mathrm{L}$ of a $0.5 \mathrm{mg} / \mathrm{mL}$ solution of MTT reagent previously prepared in DMEM were added to each well. After another four hours of incubation, the MTT reagent was removed and $300 \mu \mathrm{L}$ of DMSO were added to end the reaction. After shaking briefly, the plate was analyzed at $570 \mathrm{~nm}$ using a BioTek Synergy H4 plate reader (BioTek 
Instruments Inc., Winooski, VT, USA) to determine the relative amounts of live cells present in the sample. These values were reported as a percentage of the untreated control.

\subsubsection{VEGF-A Inhibition}

ARPE-19 cells were seeded in a 48 -well plate and incubated at $37{ }^{\circ} \mathrm{C}$ with $5 \% \mathrm{CO}_{2}$ to achieve confluence and treated with each of the NP formulations at a final concentration of $0.5 \mu \mathrm{M}$. After $72 \mathrm{~h}$, the expression of VEGF-A was quantified via enzyme-linked immunosorbent assay (ELISA) (Human VEGFA ELISA kit, Thermo Scientific, Waltham, MA, USA). Media samples were collected and analyzed using the Synergy H4 plate reader (Biotek Industries, Inc., Winooski, VT, USA) at $450 \mathrm{~nm}$ and $550 \mathrm{~nm}$. VEGF-A expression was calculated as follows:

$\%$ Expression $=($ absorbance $450 \mathrm{~nm}-$ absorbance $550 \mathrm{~nm}) /($ Control absorbance $450 \mathrm{~nm}-$ Control absorbance $550 \mathrm{~nm}) \times 100 \%$.

\subsection{Statistical Analysis}

Statistical analyses were carried out using GraphPad Prism 5, Version 5.02. Comparisons of each concentration of NP treatment, on both cell viability and VEGF-A expression, were completed using two-way ANOVA with Bonferroni post-tests to compare each treatment to the control, as well as other concentrations (if applicable). All results are written as mean values $\pm \mathrm{SD}$.

\section{Results}

\subsection{Nanoparticle Characterization}

The diameter and PDI of the AFL and blank NPs were found in triplicate via DLS. AFL-NPs were larger than their respective blanks (Table 1). The PDI was consistently less than 1, indicating a uniform size distribution (Figure 2A).

Table 1. The characteristics of aflibercept NPs $(n=3$, mean value \pm SD).

\begin{tabular}{ccccc}
\hline NP Type & Diameter $(\mathbf{n m})$ & PDI & \%EE & \%DL \\
\hline Blank & $169.91 \pm 4.29$ & $0.050 \pm 0.077$ & - & - \\
AFL-NPs & $243.13 \pm 17.64$ & $0.201 \pm 0.071$ & $75.76 \pm 2.59$ & $7.76 \pm 0.24$ \\
\hline
\end{tabular}

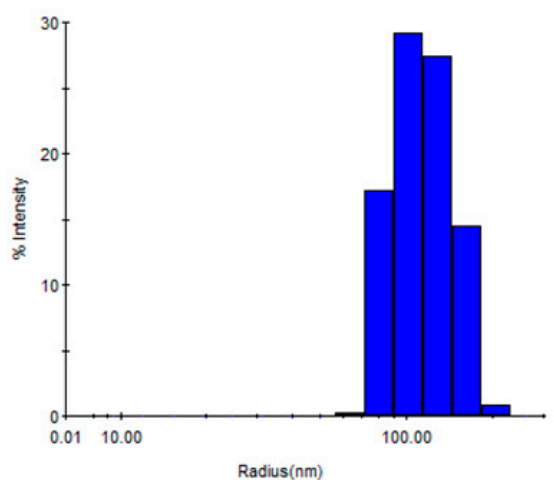

(A)

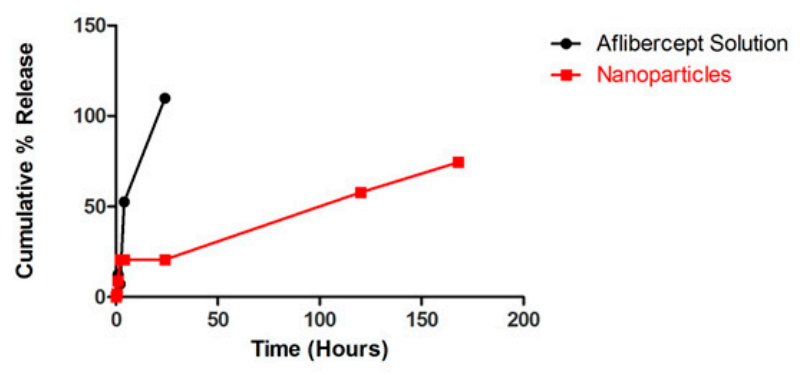

(B)

Figure 2. AFL-NPs were characterized for (A) size distribution and (B) in vitro release profile compared to AFL solution. 


\subsection{Scanning Electron Microscopy (SEM)}

AFL and blank NPs were visualized using SEM (Figure 3). Inspection showed that the NPs were spherical. The size and uniformity of the NPs corroborated with data determined via DLS.

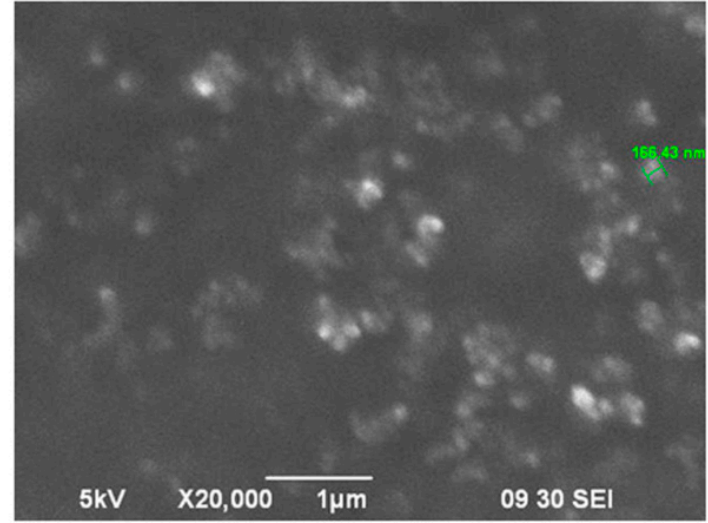

(A)

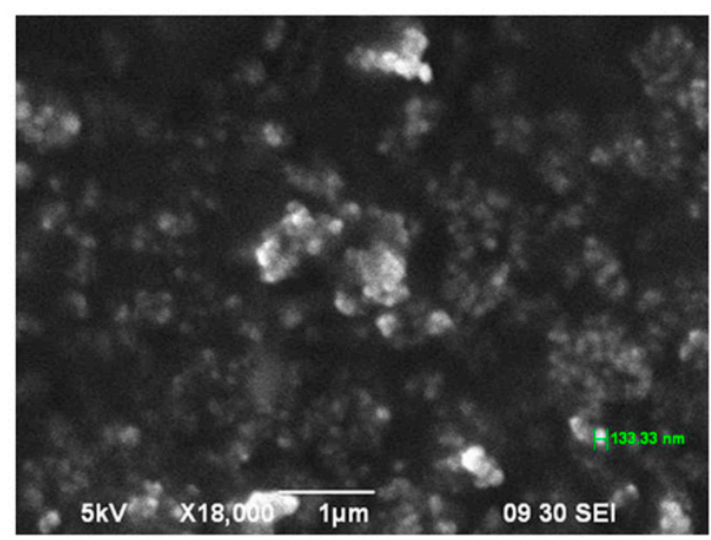

(B)

Figure 3. SEM micrographs of AFL-NPs were obtained at (A) $18,000 \times$ and (B) 20,000 $\times$ magnification. Both images were obtained using $5 \mathrm{kV}$ acceleration voltage.

\subsection{Encapsulation Efficiency and Drug Loading}

The EE and DL of each NP formulation was determined via VIS spectroscopy after analysis with the BCA protein assay. A standard curve of AFL in methanol was prepared to determine the concentration of AFL present in the NP fraction $\left(r^{2}=0.9247\right)$ (not shown). The NPs demonstrated an EE of $75.76 \pm 2.59 \%$ and DL of $7.76 \pm 0.24 \%$ (Table 1 ).

\subsection{In Vitro Release}

The rate of drug release from the NP formulation versus AFL in free solution was examined over seven days in $100 \mathrm{~mL} 1 \times \mathrm{PBS}$ at $37^{\circ} \mathrm{C}$. AFL was fully released by solution within $24 \mathrm{~h}$. Comparatively, the NPs released $74.49 \%$ in seven days. An initial burst release is demonstrated from the NPs in the first $2 \mathrm{~h}$ (Figure 2B).

\subsection{Cytotoxicity}

The cytotoxicity of blank NPs, AFL NPs and AFL solution to ARPE-19 cells were determined via MTT assay. After 24 hours, $0.5 \mu \mathrm{M}$ AFL NPs and blank NPs reduced cell viability in ARPE-19 cells by $30.11 \pm 0.344 \%$ and $27.24 \pm 5.22 \%$, respectively compared to $17.29 \pm 4.44 \%$ reduction caused by AFL. The $1 \mu \mathrm{M}$ treatments of AFL NPs and blank NPs resulted in a $41.29 \pm 10.99 \%$ and $40.87 \pm 7.15 \%$ reduction in cell viability, and the AFL reduced viability by $21.16 \pm 9.37 \%$. The differences between the two concentrations of each treatment were considered insignificant $(p<0.05)$. Both NPs at each concentration showed significant toxicity compared to the control $(p<0.001)$. However, the AFL-loaded NPs showed no significant difference in cytotoxicity compared to the blank NPs (Figure 4A).

\subsection{VEGF-A Inhibition}

The effect of AFL and AFL NPs on the VEGF-A expression of ARPE-19 cells was examined via ELISA. After 72 h, VEGF-A was not significantly reduced by $0.5 \mu \mathrm{M}$ AFL solution or AFL NPs. AFL solution reduced VEGF-A expression by $21.7 \pm 16.4 \%$ and AFL NPs reduced expression by $0.6 \pm 11.3 \%$ (Figure $4 \mathrm{~B}$ ). It must be noted that, though AFL solution is fully released into the surrounding media within $72 \mathrm{~h}$, AFL NPs take over seven days to fully release (Figure 2B). 


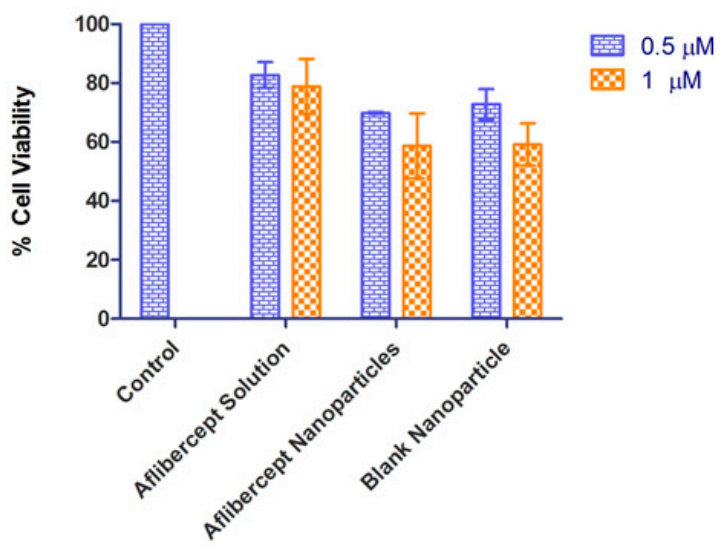

(A)

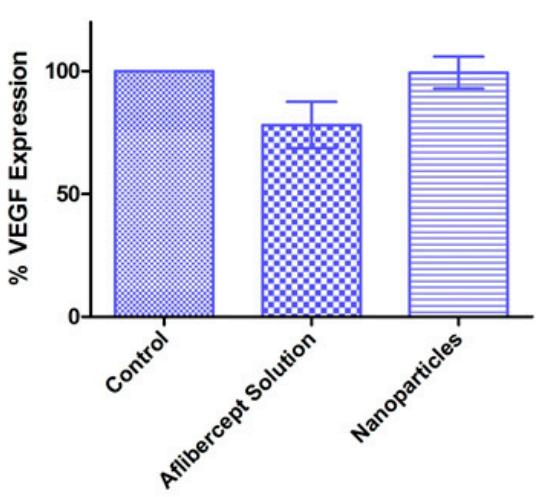

(B)

Figure 4. (A) AFL solution was non-toxic. AFL-NPs demonstrated similar cytotoxicity in ARPE-19 cells to blank NPs ( $n=3$, mean value \pm SD); (B) after $72 \mathrm{~h}$, VEGF-A expression by ARPE-19 cells was reduced post-treatment $(0.5 \mu \mathrm{M})$ with AFL and AFL NPs $(n=3$, mean $\pm \mathrm{SD})$.

\section{Discussion}

The double emulsion diffusion method was used to prepare AFL NPs. Particle size data revealed that the drug-loaded NPs were $73 \mathrm{~nm}$ larger in diameter than similarly prepared blank NPs, confirming the presence of the drug. A NP of approximately $200 \mathrm{~nm}$ in diameter is ideal to localize to retinal pigment epithelial (RPE) cells; this is indeed demonstrated by the AFL NPs (Table 1). Additionally, the PDI of each formulation remained below one, demonstrating a uniform size distribution (Figure 2A). SEM micrographs showed that the NPs possessed a spherical morphology (Figure 3). Spherical NPs possess a high surface area to volume ratio compared to other shapes (rod, cube, etc.) resulting in a more reactive surface and ultimately more opportunities to produce a therapeutic effect [20]. Furthermore, the NPs demonstrated a Gaussian size distribution (0.2 PDI) thereby reducing any variability in this effect among the individual NPs (Figure 2A). Protein assay showed that the NPs encapsulated $75.76 \pm 2.59 \%$ of the drug used in NP preparation and $7.76 \pm 0.24 \%$ of the NP mass consisted of drug. As drug loading is a ratio of drug mass to NP total mass, this value may be increased by adding a higher ratio of drug to polymer during NP preparation. However, it has been previously noted that these changes have adverse effects on shape uniformity [21]. These results were consistently reproducible (data not shown) and corroborated with previously published studies [21-23].

Cytotoxicity studies demonstrated that free AFL is non-toxic. After $24 \mathrm{~h}, 0.5 \mu \mathrm{M}$ and $1 \mu \mathrm{M}$ concentrations of both AFL NPs and blank NPs significantly reduced cell viability in ARPE-19 cells $(p<0.001)$. However, there was no significant difference in the toxicity of the AFL NPs compared to blank NPs at each concentration (Figure 4A), meaning that this toxicity is due to the use of NPs rather than any inherent cytotoxicity of AFL. This may be due to the method of in vitro testing; if NPs settled to the flat bottom of the wells any cells trapped underneath would be suffocated. A similar scenario was observed by Irfan et al. as silica NPs produced sedimentation during an LDH assay [24]. They suggest that this is due to dose concentration and aggregation. Perhaps varying these factors would produce different results. The eye's natural circulation prevents this adverse effect in vivo.

After $72 \mathrm{~h}$, VEGF-A was significantly reduced in ARPE-19 cells by $0.5 \mu \mathrm{M}$ AFL solution but not by the same concentration of AFL NPs (Figure 4B). It must be noted that, though AFL solution is fully released into the surrounding media within $72 \mathrm{~h}$, AFL NPs take over seven days to fully release (Figure 2B). In vitro release studies showed that in $72 \mathrm{~h}$, less than $57 \%$ of AFL was released into the surrounding media (Figure 2B). The sustained release properties of the NPs account for the low VEGF-A reduction by the AFL NPs. Hirani et al. reported a similar effect with triamcinolone acetonide. More potent inhibitory properties were demonstrated after $72 \mathrm{~h}$ compared to $12 \mathrm{~h}$ of treatment [12]. PLGA NPs formulated by Patel et al. illustrated a similar in vitro release profile with $25 \%$ of drug 
released after $48 \mathrm{~h}$ [25]. These sustained release properties allow the NPs to deliver a more powerful effect in vivo.

The current study demonstrates the potential of a novel nanoformulation containing AFL for the inhibition of VEGF in vitro. Further in vitro studies will be needed to demonstrate VEGF inhibition by the nanoformulation as well as AFL solution. Future in vivo studies will be carried out in a laser-induced choroidal neovascularization mouse model. The efficacy, toxicity, biodistribution and pharmacokinetics will be examined in this manner. Further clinical studies may be conducted in a human population to analyze the total effect of the nanoformulation. In summary, our nanoformulation of AFL shows potential as a protein drug delivery vehicle for the amelioration of ocular neovascularization in vitro.

\section{Conclusions}

Polymeric NPs were prepared for the sustained delivery of the protein aflibercept. The NPs were approximately $200 \mathrm{~nm}$ in diameter; an appropriate size for ocular therapeutics. The NPs were uniformly distributed and possessed a spherical morphology. The NPs demonstrated a sustained drug release over seven days and were not significantly more toxic to ARPE-19 cells than similarly prepared blank NPs. VEGF-A reduction in ARPE-19 cells was not significant after $72 \mathrm{~h}$ due to the sustained release property of the NPs. Future in vivo studies are needed to determine the effect of the NPs on live animal tissue as well as the clinical viability of the NPs in humans. Overall, aflibercept NPs demonstrated promising properties as a protein delivery vehicle for the future treatment of AMD and other neovascular conditions.

Author Contributions: Conceptualization, S.J.K., A.H., B.M., and V.S.; methodology, A.H., S.J.K., and V.S.; validation, S.J.K. and A.H.; formal analysis, S.J.K. and A.H.; investigation, S.J.K., V.S., A.S., K.H.; resources, V.S. and B.M.; data curation, S.J.K. and A.H.; writing-original draft preparation, S.J.K. and V.S.; writing-review and editing, A.H., S.V.G., and V.S.; visualization, S.J.K.; supervision, V.S., A.H., and S.J.K.; project administration, V.S., A.H., and S.J.K.; funding acquisition, A.H., S.V.G., and V.S.

Funding: This research was funded by the USF College of Pharmacy SEED Grant.

Acknowledgments: Special thanks to Amanda Garces from the USF Lisa Muma Weitz Laboratory for Advanced Microscopy \& Cell Imaging for her training and use of the scanning electron microscope. Thank you to all of the volunteers in Sutariya's lab for their support and assistance.

Conflicts of Interest: The authors declare no conflicts of interest. The funders had no role in the design of the study; in the collection, analyses, or interpretation of data; in the writing of the manuscript, and in the decision to publish the results.

\section{References}

1. CADTH. Aflibercept (Eylea): Treatment of Neovascular (Wet) Age-Related Macular Degeneration (Wamd); CADTH: Ottawa, ON, USA, 2015.

2. Sato, T.; Takeuchi, M.; Karasawa, Y.; Enoki, T.; Ito, M. Intraocular inflammatory cytokines in patients with neovascular age-related macular degeneration before and after initiation of intravitreal injection of anti-vegf inhibitor. Sci. Rep. 2018, 8, 1098. [CrossRef] [PubMed]

3. Low, A.; Kansagara, D.; Freeman, M.; Fu, R.; Bhavsar, K.; Faridi, A.; Kondo, K.; Paynter, R. Comparative Clinical and Economic Effectiveness of Anti-Vascular Endothelial Growth Factor Agents; Va Esp Project \#05-225; Department of Veterans Affairs (US): Washington, DC, USA, 2017.

4. Van Wijngaarden, P.; Coster, D.J.; Williams, K.A. Inhibitors of ocular neovascularization: Promises and potential problems. JAMA 2005, 293, 1509-1513. [CrossRef] [PubMed]

5. Subhani, S.; Vavilala, D.T.; Mukherji, M. Hif inhibitors for ischemic retinopathies and cancers: Options beyond anti-vegf therapies. Angiogenesis 2016, 257-273. [CrossRef] [PubMed]

6. Del Amo, E.M.; Rimpela, A.-K.; Heikkinen, E.; Kari, O.K.; Ramsay, E.; Lajunen, T.; Schmitt, M.; Pelkonen, L.; Bhattacharya, M.; Richardson, D.; et al. Pharmacokinetic aspects of retinal drug delivery. Prog. Retin. Eye Res. 2017, 57, 134-185. [CrossRef] [PubMed] 
7. Cunningham, M.; Edelman, J.; Kaushal, S. Intravitreal steroids for macular edema: The past, the present, and the future. Surv. Ophthalmol. 2008, 53, 139-149. [CrossRef] [PubMed]

8. Reichle, M. Complications of intravitreal steroid injections. Optometry 2005, 76, 450-460. [CrossRef] [PubMed]

9. Sinha, V.; Trehan, A. Biodegradable microspheres for protein delivery. J Control. Release 2003, 90, $261-280$. [CrossRef]

10. Hirani, A.; Pathak, Y. Introduction to nanotechnology with special reference to ophthalmic delivery. In Nano-Biomaterials for Ophthalmic Drug Delivery; Springer International Publishing: Basel, Switzerland, 2016; pp. 1-8.

11. Sanchez, A.; Tobio, M.; Gonzalez, L.; Fabra, A.; Alonso, M. Biodegradable micro- and nanoparticles as long-term delivery vehicles for interferon-alpha. Eur. J. Pharm. Sci. 2003, 18, 221-229. [CrossRef]

12. Hirani, A.; Grover, A.; Lee, Y.; Pathak, Y.; Sutariya, V. Triamcinolone acetonide nanoparticles incorporated in thermoreversible gels for age-related macular degeneration. Pharm. Dev. Technol. 2016, 21, 61-67. [CrossRef] [PubMed]

13. Geldenhuys, W.; Mbimba, T.; Bui, T.; Harrison, K.; Sutariya, V. Brain-targeted delivery of paclitaxel using glutathione-coated nanoparticles for brain cancers. J. Drug Target. 2011, 19, 837-845. [CrossRef] [PubMed]

14. Carroll, R.; Bhatia, D.; Geldenhuys, W.; Bhatia, R.; Miladore, N.; Bishayee, A.; Sutariya, V. Brain-targeted delivery of tempol-loaded nanoparticles for neurological disorders. J. Drug Target. 2010, 18, 665-674. [CrossRef] [PubMed]

15. Makadia, H.K.; Siegel, S.J. Poly lactic-co-glycolic acid (plga) as biodegradable controlled drug delivery carrier. Polymers 2011, 3, 1377-1397. [CrossRef] [PubMed]

16. Booysen, E.; Bezuidenhout, M.; van Staden, A.D.P.; Dimitrov, D.; Deane, S.M.; Dicks, L.M. Antibacterial activity of vancomycin encapsulated in poly(dl-lactide-co-glycolide) nanoparticles using electrospraying. Probiotics Antimicrob. Proteins 2018, 1-7. [CrossRef] [PubMed]

17. Feczko, T.; Toth, J.; Dosa, G.; Gyenis, J. Optimization of protein encapsulation in plga nanoparticles. Chem. Eng. Process. 2011, 50, 757-765. [CrossRef]

18. Swed, A.; Cordonnier, T.; Fleury, F.; Boury, F. Protein encapsulation into plga nanoparticles by a novel phase separation method using non-toxic solvents. J. Nanomed. Nanotechnol. 2014, 5, 241. [CrossRef]

19. D'Souza, S.S.; DeLuca, P.P. Development of a dialysis in vitro release method for biodegradable microspheres. AAPS PharmSciTech 2005, 6, E323-E328. [CrossRef] [PubMed]

20. Gatoo, M.A.; Naseem, S.; Arfat, M.Y.; Dar, A.M.; Qasim, K.; Zubair, S. Physicochemical properties of nanomaterials: Implication in associated toxic manifestations. Biomed. Res. Int. 2014, 2014, 498420. [CrossRef] [PubMed]

21. Li, F.; Hurley, B.; Liu, Y.; Leonard, B.; Griffith, M. Controlled release of bevacizumab through nanospheres for extended treatment of age-related macular degeneration. Open Ophthalmol. J. 2012, 6, 54-58. [CrossRef] [PubMed]

22. Varshochian, R.; Riazi-Esfahani, M.; Jeddi-Tehrani, M.; Mahmoudi, A.; Aghazedeh, S.; Mahmod, M.; Movassat, M.; Atyabi, F.; Sabzevari, A.; Dinarvand, R. Albuminated plga nanoparticles containing bevacizumab intended for ocularneovascularization treatment. J. Biomed. Mater. Res. A 2015, 103A, 3148-3156. [CrossRef] [PubMed]

23. McCall, R.L.; Sirianni, R.W. Plga nanoparticles formed by single- or double-emulsion with vitamin e-tpgs. J. Vis. Exp. 2013, 2013, 51015. [CrossRef] [PubMed]

24. Irfan, A.; Cauchi, M.; Edmands, W.; Gooderham, N.J.; Njuguna, J.; Zhu, H. Assessment of temporal dose-toxicity relationship of fumed silica nanoparticle in human lung a549 cells by conventional cytotoxicity and 1h-nmr-based extracellular metabonomic assays. Toxicol. Sci. 2014, 138, 354-364. [CrossRef] [PubMed]

25. Patel, J.; Amrutiya, J.; Bhatt, P.; Javia, A.; Jain, M.; Misra, A. Targeted delivery of monoclonal antibody conjugated docetaxel loaded plga nanoparticles into egfr overexpressed lung tumour cells. J. Microencapsul. 2018, 35, 204-217. [CrossRef] [PubMed]

(c) 2018 by the authors. Licensee MDPI, Basel, Switzerland. This article is an open access article distributed under the terms and conditions of the Creative Commons Attribution (CC BY) license (http:// creativecommons.org/licenses/by/4.0/). 